\title{
HAMBATAN KOMISI C DEWAN PERWAKILAN RAKYAT KABUPATEN PIDIE DALAM PENGAWASAN IZIN MENDIRIKAN BANGUNAN (IMB) DI KABUPATEN PIDIE
}

\author{
T. Yasman Saputra \\ Program Studi Ilmu Hukum Fakultas Hukum Universitas Jabal Ghafur. \\ Email: teukuyasman@unigha.ac.id
}

\begin{abstract}
ABSTRAK
Keberadaan IMB salah satunya berfungsi sebagai kontrol Pemerintah Daerah terhadap pendataan fisik kota dalam perencanaan, pengawasan, dan penerbitan pembangunan kota yang terarah. Fungsi lainnya memberikan kepastian hukum bagi pemilik bangunan. Penelitian telah dilakukan pada tahun 2012 di Kabupaten Pidie, tujuannya adalah untuk mengetahui hambatan Komisi C DPRK Kabupaten Pidie dalam pengawasan perizinan izin mendirikan bangunan. Penelitian ini merupakan penelitian hukum normatif yang didukung oleh yuridis emperis. Data dianalisis secara kualitatif. Hasil penelitian menunjukkan sejumlah hambatan baik internal maupun eksternal. Hamnatan internalnya adalah keterbatasan Sumber Daya Manusia (SDM) sedangkan hambatan eksternalnya adalah terkait peran masyarakat yang bersikap apatis.
\end{abstract}

Kata kunci;,Komisi C, DPRK Pidie, hambatan.

\section{Pendahuluan}

Komisi dalam dewan perwakilan rakyat meruapak alat kelengkapan DPRD yang bersifat tetap dan dibentuk pada awal masa jabatan keanggotaan DPRD. Setiap anggota DPRD kecuali pimpinan DPRD wajib menjadi anggota komisi dan jika terjadi perpindahan antar komisi hanya dapat dilakukan atas dasar usulan fraksi dan diputuskan dalam rapat paripurna DPRD (Wasistiono, 2009). Arti atau pengertian IMB (Izin Mendirikan Bangunan) adalah produk hukum yang berisi persetujuan atau perizinan yang dikeluarkan oleh Kepala Daerah Setempat (Pemerintah kabupaten / kota) dan wajib dimiliki / diurus pemilik bangunan yang ingin membangun, merobohkan, menambah / mengurangi luas, ataupun merenovasi suatu bangunan. Kehadiran IMB (izin mendirikan bangunan) pada sebuah bangunan sangatlah penting, karena bertujuan untuk menciptakan tata letak bangunan yang aman dan sesuai dengan peruntukan lahan. Bahkan keberadaan IMB juga sangat dibutuhkan ketika terjadi transaksi jual beli rumah. Pemilik rumah yang tidak memiliki IMB nantinya akan dikenakan denda 10 persen dari nilai bangunan, rumah pun juga bisa dibongkar.

Komisi C DPRK Kabupaten Pidie memiliki peran dalam hal perizinan di Kabupaten Pidie. Izin mendirikan bangunan (IMB) merupakan kewenangan Pemerintah Kabupaten dan Kota. Dalam implementasinya, Komisi C DPRK Kabupaten Pidie melakukan fungsinya sebagai pengawas pemerintah daerah dalam perizinan, karena Pemerintah Kabupaten Pidie sendiiri memiliki potensi sumber daya alam yang baik, yang nantinya mempengaruhi iklim investasi di daerah Pidie. IMB berfungsi supaya pemerintah daerah dapat mengontrol prndataan fisik kota sebagai dasar yang sangat penting bagi perencanaan, pengawasan, dan penerbitan pembanguna kota yang terarah dan sangat bermanfaat pula bagi pemilik bangunan karena memberikan kepastian hokum untuk bernbagai keperluan, antara lain dalam hal pemindahan hak bangunan kepada pohak lain (seperti jual beli, pewarisan, penghibahan).

Permasalah di lapangan dijumpai banyaknya bangunan yang sedang dibangun 
di sepanjang rusa jalan nasional tidak memiliki IMB, pemerintah sedianya peka dan lebih cepat mengambil kebiajkan terhadap pembangunan sejumlah ruko yang tidak meiliki IMB agar tidak terus menjamur. Karena selain mrnyrbsbksn kesemrautan lalulintas, juga mrmbuat ruas jalan Negara menjadi sempit, sehingga rawan kecelakaan. Melihat hal tersebut, perlu dikaji mengenai hambatan komisi C DPRK Kabupaten Pidie terhadap pengawasan Izin mendirikan Bangunan (IMB) di Kabupaten Pidie.

Permasalahan dalam penelitian ini dibatasi pada hambatan yang dihadapi Komisi C DPRK Kabupaten Pidie terhadap pengawasan izin mendirikan bangunan, serta upaya yang dilakukan untuk mengatasi hsmbstsn tersebut. Penelitian ini diharapkan dapat memberikan manfaat secara teroritis untuk menambah wawasan khasanah ilmu penegtahuan dalam bidang hokum administrasi Negara terutama di bidang perizinan. Secara praktis, penelitian ini diharapkan dapat memberikan gambaran kepada masyarakat mengenai hambatan komisi C DPRK Pidie dalam hal pengawasan izin endidirkan bnagunan.

\section{Metode Penelitian}

Penelitian ini dilakukan dengan pendekatan yuridis normative yang didukung oleh yuridis emperis. Pendekatan yuridis normative yaitu penelitian yang dilakukan dengan terlebih dahulu mneeliti bahan-bahan kepustakaan (Library Reseacrh) yang relevan dengan permasalahn yang dirlwiti. Pendekatan yuridis emperis dilakukan dengan studi lapangan dalam hal ini di DPRK Pidie opada Komisi C mengenai hambatan yang didpaat komisi $\mathrm{C}$ dalam pengawasaan perizinan iiizin mendirikan bangunan.

\section{Lokasi, Populasi, dan Sampel Penelitian}

Pemilihan lokasi di lakukan di Komosi

C DPRK Kabupaten Pidie, didasarkan pada bahwasanya Komis C merupakan momisi yang memiliki peran oenting dalam melakukan fungsi prngawasan dsalsm perizinan di kabupaten Pidie terutama dalam hal izin mendirikan bangunan

Populasi penelitoiannya adalag seluruh anggota DPRK Kabupaten Pidie dan samplenya adalah anggota Komisi C DPRK Kabupaten Pidie.

\section{Prosedur pengambilan dan pengumpulan data.}

Pengumpulan data primer dilakukan dengan wawancara berdasarkan pedoman wawancara yang telah disususn dan disiapkan sebelumnya. Data sekunder didapat dari lembaga hukum yang terkait dengan Penelitian ini. adapun data sekunder diperoleh melalui telaah kepustakaan.

\section{Analisis data}

Analisis data dilakukan dengan model analisis kualitatif, dimana data-data yabng diperkukan guna menjawab permasalahan, baik data primer maupun data sejunder, dikumpulkan iuntuk kemudian diseleksi, dipilah-pilah berdasarksn kualitas dsn relevansinya utnuk kemudisn durentukan data yang penting dan data yang tidak penting untuk menjawab permasalahan.

\section{Hasil penelitian dan pembahasan}

Hambatan yang dihadapi komisi $\mathrm{C}$ DPRK pidie dalam hal izin mendirikan bnagunan adalah sebagai berikut:

1. Hambatan internal

Adapun hambatan internal yang dihadapi Komisi C Pidie dalam hal perizinan mendirikan bangunan adalah sebagai berikut:

a. Hambatan secara internal adalah terkait sumber daya manusia (SDM) anggota DPRK Pidie. Hal tersebut dikarenakan latar belaknag pendidikan anggota DPRK yang berasal dari berbagai disiplin ilmu, sehingga untuk memproses perancangan qanun yang akan disesuaikan tentunya mengalami kendala.

b. Tim legislasi DPRK Pidie dalam merancang qanun tentang izin mendirikan bangunan hanya menganalisis legal drafting yang diajukan Pemerintah Kabupaten saja, tanoa menganalisis keadaan di masyarakat. 
c. Kurang maksimal pengawasan DPRK, hal tersebut dikarenakan pengajuan RAPBK sering terlambat melewati jadwal yang ditentukan.

d. Kurang berfungsinya alat kelengkapan dewan, contoh kurangnya rapat-rapat konsultasi dengan pihak terkait.

2. Hambatan eksternal

Adapun hambatan secara eksternal yang dihadapi komisi C DPRK Pidie adalah sebagai berikut:

a. Lambannya pengajuan legal drafting qanun oleh executive, maka dengan sendirinya pengerjaan rapat dewan tidak maksimal.

b. Hambatan eksternal lainnya adalah terkait peran masyarakat, hal tersebut dikarenakan pemerintah kabupaten pidie dalam sosialisasi qanun nomor 23 tahun 2002 kepada masyarakat sangat rendah, sehingga masyarakat tidak begitu memahami qanun yang diterapkan.

3. Hambatan dalam melaksanakan fungsi pengawasan oleh DPRD

a. Belum tersusunnya agenda pengawasan DPRD

Di dalam menjalankan fungsi pengawasan seyogyanya DPRD memiliki rencana atau agenda pengawasan meliputi apa, siapa yang akan diawasi, mengapa harus diawasi serta kapan dan bagaimana pengawasan tersebut dilakukan. Para wakil rakyat belum memandang pengawasan sebagai proses manajerial dan politik yang memerlukan langkah-langkah perencanaan, pengorganisasian, pelaksanaan dan pengedalian. Pengawasan oleh DPRD yang tidak sesuai ranah pengawasan DPRDyakni ranah kebijakan dan politik serta tidak terprogram, akan membawa dampak pada munculnya hal-hal sebagai berikut:

1) Ruang lingkup pengawasan DPRD terabaikan
2) Duplikasi pengawasan dengan lembaga pengawasan lainnya;

3) Kurangnya mutu pengawasan;

4) Pengawasan belum efektif.

b. Belum adanya standar, system dan prosedur bakun pengawasan DPRD Pelaksanaan pengawasaan DPRD masih dirasakan sebagai suatu pengawasan yang reaktif dan sporadic, tanpa terencana dan tersistem dalam pelaksanaannya. Selain itu standar pengawasan, system dan prosedur serta administrasi pengawasan belum disusunj secara baik.

c. Partisipasi masyarakat belum optimal Pelaksanaan fungsi pengawasan DPRD diharapkan dapat mendorong pihak pemda agar perda yang sudah ada dapat diimplementasikan seara konsisten dan berkelanjutan supaya tercipta tertib hokum dan kepastian bukum, sehingga dapat memberikan manfaat besar bagi masyarakat. Sebagai pemilik kedaulatan, masyarakat memilih hak untuk dilakukan optimaisasi saluran pengawasan masyarakat baik melalui wakilnya di DPRD maupun melalui media, seperti media cetak dan elektronik, kotak pos, pesan singkat, Lembaga Swadaya Masyarakat atau lainnya. Fakta yang ada menunjukkan bahwa penyaluran pengawasan masyarakat sampai saat ini belum terlaksana dengan optimal.

\section{Upaya yang dilakukan dalam mengatasi hambatan dalam hal izin mendirikan bangunan}

1. Upaya internal

Adapun upayas internal yang dilakukan DPRK Pidie adalah sebagai berikut:

a. Mengikuti pelatihan-pelatihan dalam menambah pengetahuan dalam rangkan pelaksanaa tugas tugas masing-masing bagi anggota DPRK.

b. Tim legislasi DPRK Pidie harus menerima aspirasi masyarakat 
tentang penetapan IMB dan konsultasi denagn pihak terkait.

c. Para anggota DPRK Pidie harus memahami tata gtertib yang sudah ditetapkan.

d. Masing-masing alat kelangkapan dewan supaya memperbanyak rapatrapat konsultasi dengan miytra kerjanya.

e. Memperbanyak pemantauan ke lokasi yang telah ditetapkan.

f. Memperbanyak peninjauan ke lokasilokasi yaitu dalam bentuk pansus.

g. Upaya eksternal

Adapun upaya eksternal yang dilakukan DPRK Pidie adalah sebagai berikut:

1. Dewan menyurati Pemerintah Kabupaten Pidie agar poengajuan Qanun segera disampaiakn ke DPRK, supaya dapat dilakukan pemabhasan bersama, sehingga kegiatan dewan tidak terganggu dengan kegiatan jadwal yang lain.

2. Menagajak masyarakat untuk berperan aktif dalam hal terkait izin mendirikan bangunan agar dapat meminimalisirnpelanggaran atata ruang.

\section{Kesimpulan}

1. Hambatan secara internal yang dihadapai Komisi C DPRK Pidie dalam melakukan pengawasan adalah terait sumber daya manusia, dikarenakan beragamnya latar belakang pendidikan anggota DPRK

2. Hambatan secara esternal adalah lambannya pengajuan legal drafting qanun oleh exsekutif, sehingga pengerjaaan rapat dewan tidak maksimal.

3. Uapay yang dilakukan terkait pengingakatn SDM sdalah dengan mengikuti pekatihan-pelatihan.

\section{Daftar Pustaka}

Adisasmita, rahardjo, 2010. Ppembangunan kawasan dan tata Ruang, Grha Ilmu, Yogyakarta.
Budihardjo, Eko, 1997, tata Ruang Perkotaan, Alumni, Bandung.

Hadjon, Philipus M, et. Al., 1993. Pengantar Hukum Perizinan, Yuridika, Surabaya.

Sutedi, Adrian, 2010. Hukum Perizinan: dalam sector pelayanan public, Sinar Grafika, Jakarta.

Wasistiono, sadu, dan Yonatan Wiyoso, 2009, menigkatkan keinerja Dewan Perwakilan Daerah (DPRD), Fokusmedia, bandung.

Sugiyono (2013). Cara Mudah Menyusun Skripsi, Thesis, dan Disertasi. Bandung. Alfabeta. 